\title{
Endoscopic fluorescence detection of low and high grade dysplasia in Barrett's oesophagus using systemic or local 5-aminolaevulinic acid sensitisation
}

E Endlicher, R Knuechel, T Hauser, R-M Szeimies, J Schölmerich, H Messmann

\begin{abstract}
Background and aims-Barrett's oesophagus is associated with an increased risk of cancer. As dysplasia is not visible during routine endoscopy, random biopsies in the four quadrants every $1-2 \mathrm{~cm}$ are recommended. Endoscopic fluorescence detection (EFD) after sensitisation with 5-aminolaevulinic acid (5-ALA) with different modes and concentrations was assessed to optimise the technique for detection of dysplasia or early cancers. 5-ALA is converted intracellularly to protoporphyrin IX which accumulates in malignant tissue and can be detected by typical red fluorescence after illumination with blue light.
\end{abstract}

Methods-In 47 patients with Barrett's oesophagus, 10 with known dysplasia, 58 fluorescence endoscopies were performed after sensitisation with different concentrations of 5-ALA given orally $(5,10,20,30$ $\mathrm{mg} / \mathrm{kg}$ ) or locally (500-1000 $\mathrm{mg}$ ) by spraying the mucosa via a catheter. EFD was performed 4-6 hours after systemic and 1-2 hours after local sensitisation using a special light source delivering white or blue light. A total of 243 biopsies of red fluorescent $(n=113)$ and non-fluorescent areas $(n=130)$ were taken.

Department of Internal Medicine I, University of

Regensburg, Germany

E Endlicher

T Hauser

J Schölmerich

H Messmann

Department of

Dermatology,

University of

Regensburg, Germany

R-M Szeimies

Institute of Pathology, University of

Regensburg, Germany

R Knuechel

Preliminary data were presented orally at the DDW, 1998.

Correspondence to: Dr H Messmann, University of Regensburg, 93042 Regensburg, Germany. helmut.messmann(a)

klinik.uni-regensburg.de

Accepted for publication 22 August 2000 quadrant random biopsies.

(Gut 2001;48:314-319)

Keywords: Barrett's oesophagus; dysplasia; fluorescence endoscopy; 5-aminolaevulinic acid
Barrett's oesophagus is associated with an increased risk of developing carcinoma, ranging from 1 in 52 to 1 in 208 patient years. ${ }^{1-4}$ Adenocarcinoma arises from dysplasia, which is usually not visible during routine endoscopy. ${ }^{5}$ Therefore, extensive random sampling of the entire Barrett's segment is recommended with biopsies from the four quadrants every 1-2 $\mathrm{cm}$ and from any macroscopic abnormality. Nevertheless, these random biopsies are associated with an inevitable sampling error. ${ }^{6}$ There is some evidence that better tissue sampling may be achieved with a jumbo biopsy forceps. The Seattle biopsy protocol with multiple and large biopsies using a jumbo forceps can differentiate between cancer and high grade dysplasia (HGD) in all cases. ${ }^{7}$ However, this biopsy protocol is time consuming and difficult to perform in clinical practice. Furthermore, other groups were unable to confirm differentiation of HGD and early cancer in a recent trial. ${ }^{8}$

Optical guided biopsies should overcome the problem of "sampling errors". Endoscopic fluorescence detection (EFD) may be a useful procedure to avoid sampling errors in the detection of non-visible dysplasia in Barrett's oesophagus. Using a sensitiser, which accumulates selectively in tumours and dysplasia, and consecutive illumination with light at a specific wavelength, fluorescence of these lesions is induced which is not visible at normal white light endoscopy.

Among sensitisers, 5-aminolaevulinic acid (5-ALA) is an ideal substance for EFD. It is not a sensitiser itself but is converted intracellularly into the photoactive compound protoporphyrin IX (PPIX). Due to low ferrochelatase activity in tumour cells, PPIX preferentially accumulates in malignant tissue. ${ }^{9}$ Furthermore, PPIX is more selective than other photosensitisers such as Photofrin and induces skin photosensitivity lasting no longer than 24 hours. ${ }^{10}$ A further advantage of 5-ALA compared with other sensitisers is the short delay between administration of the drug and examination. Recently, we demonstrated for the first time that dysplastic lesions can be detected in an

Abbreviations used in this paper: 5-ALA, 5-aminolaevulinic acid; PPIX, protoporphyrin IX; $\mathrm{EFD}$, endoscopic fluorescence detection; MPD, minimal phototoxic dose; LGD, low grade dysplasia; HGD, high grade dysplasia; LIFS, laser induced fluorescence spectroscopy; LIFE, laser induced fluorescence endoscopy; HPD, haematoporphyrins. 
animal colitis model after sensitisation with 5-ALA. ${ }^{11}$

These data encouraged us to evaluate the potential role of fluorescence endoscopy in clinical practice. A pilot study demonstrated the possible benefit in detecting precancerous lesions in the gastrointestinal tract. ${ }^{12} \mathrm{With}$ this technique reduced "sampling error" in detecting dysplasia and less biopsies may be advantageous in future surveillance.

The aim of this study was to optimise the technique of EFD for dysplasia in patients with Barrett's oesophagus. Therefore, EFD was evaluated in a similar manner as our animal experiments using different application methods and doses of 5-ALA. Apart from the known side effects of 5-ALA, such as poor digestive tolerance or skin sensitivity, other side effects were evaluated at the lower drug doses used.

\section{Patients and methods}

PATIENT POPULATION

Fifty eight fluorescence endoscopies were performed in 47 patients (41 male, median age 60 years) with endoscopically and histologically proved Barrett's oesophagus, who gave written consent to take part in the study. The protocol was approved by the ethics committee of the medical faculty of the University of Regensburg.

Ten patients had either low (LGD) or high (HGD) grade dysplasia which were diagnosed by routine endoscopy and four quadrant biopsies 1-4 weeks before EFD. This method was used as the gold standard for evaluation of EFD. In cases of inflammation due to reflux oesophagitis, patients were treated for four weeks with proton pump inhibitors as inflammation induces false positive fluorescence. ${ }^{11}$

PRE-EXAMINATION AND STUDY CRITERIA

Patients with a history of acute or chronic liver disease as well as known porphyria were excluded. Furthermore, all patients were examined with ultrasonography, and serum liver tests (transaminases, bilirubin, alkaline phosphatase, pseudocholinesterase) were performed to exclude liver disease.

To determine if local or systemic application of 5-ALA lowers the threshold dose for phototoxic reactions (erythema, pigmentation) due to the occurrence of photosensitising amounts of PPIX in the skin, ${ }^{9}$ some of the patients undergoing EFD were tested with UVA light to assess the minimal phototoxic dose (MPD), before sensitisation, immediately, and 24 hours after endoscopy. This was performed by exposing small areas of skin to a progressive graded series of defined UVA light doses $\left(0-80 \mathrm{~J} / \mathrm{cm}^{2}\right)$. In subjects with healthy skin, the mean threshold dose of UVA, where patients develop a photoxic reaction such as erythema, is about 21 $\mathrm{J} / \mathrm{cm}^{2}$ (for details see Messmann and colleagues $\left.{ }^{13}\right)$.

All patients were monitored continuously for heart rate and blood pressure. In addition, we recorded side effects such as nausea and vomiting.

For pharmacokinetic studies, total concentrations of porphyrins in urine and serum were measured.
SENSITISATION AND FLUORESCENCE ENDOSCOPY Patients were sensitised either systemically with different concentrations of 5-ALA $(5,10,20$, $30 \mathrm{mg} / \mathrm{kg}$; Medac $\mathrm{GmbH}$, Hamburg, Germany) dissolved in orange juice, or locally (500-1000 mg) by spraying the 5-ALA solution on Barrett's mucosa with a special spray catheter (5-PWL; Olympus, Hamburg, Germany). The remaining 5-ALA solution in the stomach was aspirated with the same catheter and sprayed a second time on Barrett's mucosa. Finally, the 5-ALA solution was sucked off with the endoscope in the stomach to avoid systemic resorption. Fluorescence endoscopy was performed 4-6 hours after systemic and 1-2 hours after the initial endoscopy with local sensitisation.

Endoscopy was performed using fibrescopes (GIF Q20 and 1T20; Olympus, Hamburg, Germany). The endoscopes were connected to the light source delivering white or blue light (D-light; Storz, Tuttlingen, Germany), emitting blue light at a wavelength of 380-440 nm. During endoscopy it was possible to switch between the white and blue light modes. The endoscope was attached to a camera (Endovision Telecam SL; Storz, Tuttlingen, Germany) with an imaging processing module delivering real time fluorescence pictures. Those areas containing high PPIX concentrations appeared with characteristic red fluorescence under illumination with blue light. A yellow band pass filter (Storz, Tuttlingen, Germany) was used to connect the ocular part of the endoscope to the camera.

Endoscopy was performed in a darkened room to allow the endoscopist to adapt to the darkness. Biopsies taken from endoscopically fluorescent and non-fluorescent areas were snap frozen. For histological diagnosis, conventional $5 \mu \mathrm{m}$ cryostat sections were cut prior to and after $20 \mu \mathrm{m}$ sections for fluorescence evaluation and stained with haematoxylin and eosin. The thick sections were stored at $-20^{\circ} \mathrm{C}$ in the dark until analysis. Fluorescence examination of the $20 \mu \mathrm{m}$ sections was performed with an epi-illumination fluorescence microscope (Aristoplan Leica, Wetzlar, Germany) equipped with a $50 \mathrm{~W}$ mercury vapour lamp (Osram, München Germany). Excitation light was transmitted through a $355-425 \mathrm{~nm}$ bandpass filter, emitted through a $455 \mathrm{~nm}$ reflection short pass filter, and a $460 \mathrm{~nm}$ long pass filter. Additional haematoxylin and eosin staining was performed for the $20 \mu \mathrm{m}$ sections after photodocumentation of the specific fluorescence pattern.

\section{STATISTICAL ANALYSIS}

Descriptive values are expressed as median (range) for age, length of Barrett's oesophagus, and number of biopsies. Statistical analysis was performed using the $\chi^{2}$ test with Yates' correction. Probabilities of less than 0.05 were accepted as significant.

\section{Results}

A total of 58 fluorescence endoscopies in patients with a histologically proved Barrett's oesophagus were evaluated. In 10 patients, 
Table 1 Distribution of dysplasia positive biopsies with respect to their fluorescence

\begin{tabular}{lllcl}
\hline $\begin{array}{l}\text { 5-ALA application } \\
\text { mode }\end{array}$ & $\begin{array}{l}\text { All LGD } \\
(n)\end{array}$ & $\begin{array}{l}\text { Fluorescence } \\
\text { positive LGD (n) }\end{array}$ & $\begin{array}{l}\text { All HGD/carcinoma } \\
(n)\end{array}$ & $\begin{array}{l}\text { Fluorescence positive } \\
\text { HGD/carcinoma }(n)\end{array}$ \\
\hline $500 \mathrm{mg}$ locally & 7 & 4 & 3 & 1 \\
$5 \mathrm{mg} / \mathrm{kg}$ orally & 0 & 0 & 0 & 0 \\
$10 \mathrm{mg} / \mathrm{kg}$ orally & 5 & 3 & 10 & 9 \\
$20 \mathrm{mg} / \mathrm{kg}$ orally & 1 & 1 & 2 & 2 \\
$30 \mathrm{mg} / \mathrm{kg}$ orally & 3 & 3 & 2 & 2
\end{tabular}

5-ALA, 5-aminolaevulinic acid; LGD, low grade dysplasia; HGD, high grade dysplasia.

Table 2 Distribution of biopsies with or without dysplasia with regard to their fluorescence

\begin{tabular}{|c|c|c|c|c|}
\hline \multirow[b]{2}{*}{ 5-ALA application mode } & \multicolumn{2}{|c|}{ Dysplasia positive } & \multicolumn{2}{|c|}{ Dysplasia negative } \\
\hline & $\begin{array}{l}\text { Fluorescence } \\
\text { positive (n) }\end{array}$ & $\begin{array}{l}\text { Fluorescence } \\
\text { negative (n) }\end{array}$ & $\begin{array}{l}\text { Fluorescence } \\
\text { positive (n) }\end{array}$ & $\begin{array}{l}\text { Fluorescence } \\
\text { negative (n) }\end{array}$ \\
\hline $500 \mathrm{mg}$ locally & 6 & 4 & 27 & 59 \\
\hline $5 \mathrm{mg} / \mathrm{kg}$ orally & 0 & 0 & 18 & 23 \\
\hline $10 \mathrm{mg} / \mathrm{kg}$ orally & 12 & 3 & 18 & 23 \\
\hline $20 \mathrm{mg} / \mathrm{kg}$ orally & 3 & 0 & 20 & 21 \\
\hline $30 \mathrm{mg} / \mathrm{kg}$ orally & 5 & 0 & 16 & 6 \\
\hline
\end{tabular}

5-ALA, 5-aminolaevulinic acid.

Table 3 Sensitivity, specificity, and positive and negative predictive values per biopsies for detection of dysplastic lesions in Barrett's oesophagus after different sensitisations using 5-aminolaevulinic acid (5-ALA)

\begin{tabular}{lrcllc}
\hline $\begin{array}{l}5-\text { ALA } \\
\text { application mode }\end{array}$ & $\begin{array}{l}\text { Examinations } \\
\text { (biopsies) }(n)\end{array}$ & $\begin{array}{l}\text { Sensitivity } \\
(\%)\end{array}$ & $\begin{array}{l}\text { Specificity } \\
(\%)\end{array}$ & $\begin{array}{l}\text { Pos. predictive } \\
\text { value (\%) }\end{array}$ & $\begin{array}{l}\text { Neg.predictive } \\
\text { value (\%) }\end{array}$ \\
\hline $500 \mathrm{mg}$ locally & $22(96)$ & 60 & 69 & 18 & 94 \\
$5 \mathrm{mg} / \mathrm{kg}$ orally & $4(20)$ & - & 70 & 0 & 100 \\
$10 \mathrm{mg} / \mathrm{kg}$ orally & $13(56)$ & 80 & 56 & 40 & 88 \\
$20 \mathrm{mg} / \mathrm{kg}$ orally & $13(44)$ & 100 & 51 & 13 & 100 \\
$30 \mathrm{mg} / \mathrm{kg}$ orally & $6(27)$ & 100 & 27 & 23 & 100 \\
\hline
\end{tabular}

LGD or HGD was diagnosed on previous routine endoscopy with four quadrant biopsies every $1-2 \mathrm{~cm}$. The median length of the Barrett's segment in all patients was $6 \mathrm{~cm}$ and the median number of biopsies was four.

DETECTION OF DYSPLASIA USING EFD

A total of 243 biopsies were examined; 113 biopsies were taken from red fluorescent areas and 130 control biopsies from non-fluorescent mucosa. The number of fluorescent negative biopsies in the group sensitised with $30 \mathrm{mg} / \mathrm{kg}$ 5-ALA was low due to the high background fluorescence. In contrast, $5 \mathrm{mg} / \mathrm{kg} 5$-ALA induced only weak fluorescence and therefore the number of fluorescence positive biopsies was lower in this group.

Thirty three biopsies showed either LGD $(n=16)$ or $\mathrm{HGD} /$ carcinoma $(n=17)$. One of the $\mathrm{HGD} /$ carcinoma biopsies was fluorescence negative after sensitisation with $10 \mathrm{mg} / \mathrm{kg}$
5-ALA compared with two after local sensitisation, while five biopsies containing LGD did not fluoresce ( $n=3$ after local and $n=2$ after 10 $\mathrm{mg} / \mathrm{kg}$ 5-ALA sensitisation). Details of all biopsies containing dysplasia are given in table 1.

Ten patients presented initially with LGD or HGD. Using EFD we detected dysplasia and two carcinomas in three more patients not visible during routine endoscopy with four quadrant biopsies. The number of patients was too low to calculate sensitivity, specificity, or positive and negative predictive values. Therefore, we used the number of biopsies as a first step to calculate these values as our aim was to show the superiority of fluorescence guided biopsies by detecting suspicious lesions.

Sensitivity, specificity, and positive and negative predictive values for detection of dysplasia varied with different doses of 5-ALA but also with the administration mode. After inclusion of 20 patients an interim analysis demonstrated that a dose of $5 \mathrm{mg} / \mathrm{kg}$ was too low for detection of dysplasia whereas $30 \mathrm{mg} / \mathrm{kg}$ 5-ALA orally induced $100 \%$ sensitivity but was associated with a decrease in specificity. Therefore, subsequent patients were sensitised with mainly 10 or $20 \mathrm{mg} / \mathrm{kg} 5$-ALA orally or locally to optimise the sensitisation mode. In table 2 details of biopsies with or without dysplasia and their fluorescence status are given. Table 3 shows the different sensitivity, specificity, and positive and negative predictive values for all patient groups. Figure 1 shows a typical red fluorescent area in a Barrett's segment after oral sensitisation with $20 \mathrm{mg} / \mathrm{kg}$ 5-ALA.

False positive fluorescence was induced mainly by inflammation and metaplasia. In addition, reflux of bile into the oesophagus disturbed the EFD of dysplasia as bile was associated with an intensive red fluorescence.

Fluorescence of histology sections revealed distinct staining. Specific PPIX red fluorescence was found in dysplastic epithelium and intestinal metaplasia while simple metaplasia with cardiac- or fundus-type epithelium lacked epithelial PPIX positivity (fig 2A-D).

\section{SIDE EFFECTS}

Skin phototoxicity

5-ALA induced only limited skin phototoxicity which lasted for no longer than 24 hours.

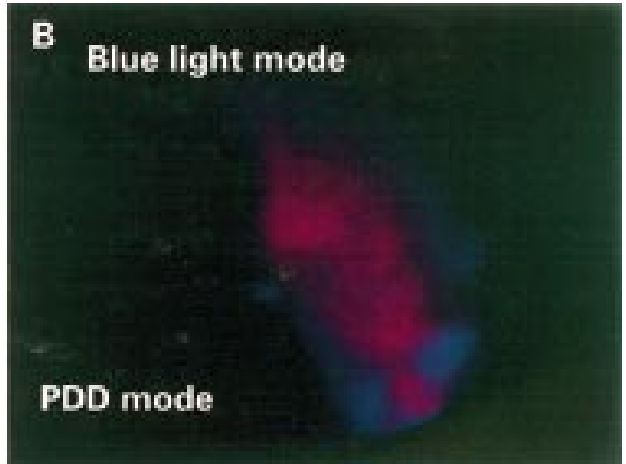

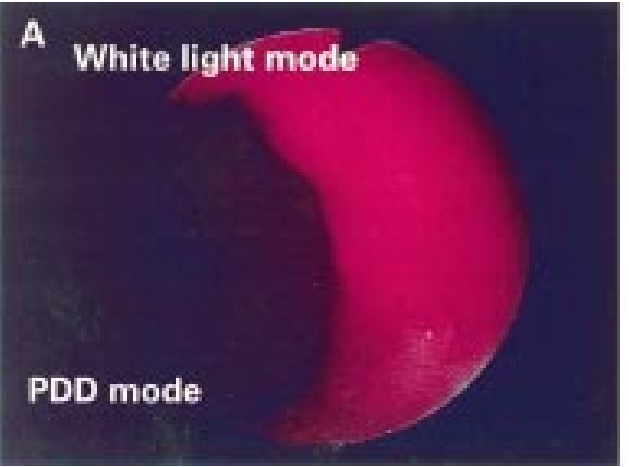

Figure 1 Endoscopic fluorescence pictures. Comparative presentation of regular endoscopy with white light $(A)$ and fluorescence endoscopy (B), four hours after sensitisation with $20 \mathrm{mg} / \mathrm{kg}$ 5-aminolaevulinic acid. Selective red fluorescence area within the Barrett's segment presented high grade dysplasia. 

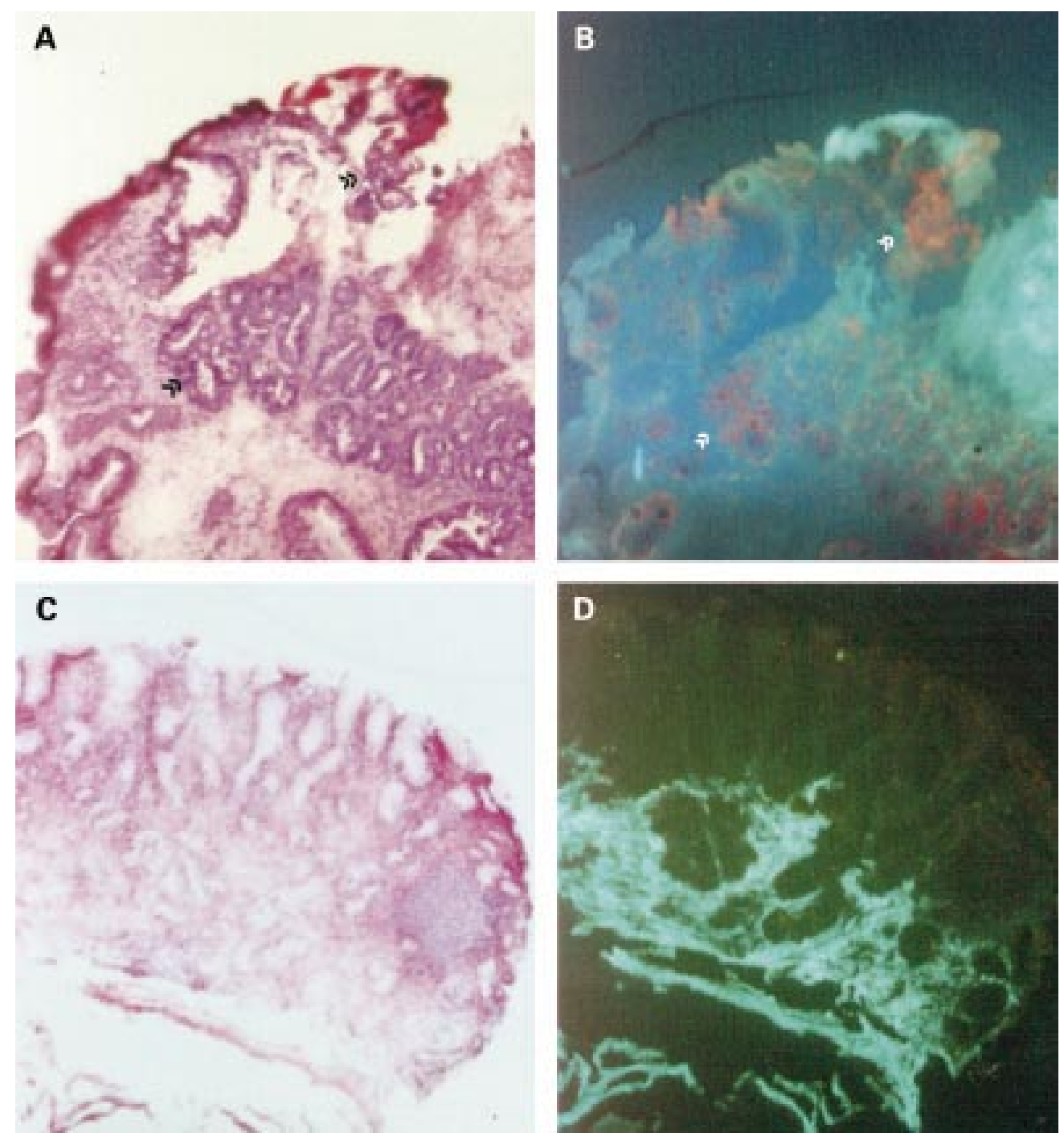

Figure 2 Fluorescence microscopy. (A, B) Frozen section $(20 \mu \mathrm{m})$ from a biopsy of endoscopically red fluorescent positive mucosa in Barrett's oesophagus. (A) Fluorescence of the section and subsequent haematoxylin-eosin stained identical section (B). Enlargement 25×. Fluorescence was limited to the epithelium, mature foveolar epithelium was negative (left side, surface), and distinct and patchy positive fluorescence was related to intestinal metaplasia (specialised epithelium with goblet cells) and to dysplasia (arrows). (C,D) Frozen section $(20 \mu \mathrm{m})$ from a biopsy of endoscopically red fluorescent negative mucosa in Barrett's oesophagus. (C) Fluorescence of section indicating only green autofluorescence, and subsequently haematoxylin-eosin stained identical section (D), showing the histology of the gastric mucosa (simple metaplasia). Enlargement 25×. Comment: diagnosis was verified by adjacent regular $5 \mu m$ sections but identical $20 \mu m$ sections are shown here to precisely relate fluorescence to morphology.

However, 4-6 hours after systemic sensitisation, the optimal time for EFD, all patients were photosensitive. At that time, the MPD in those patients tested $(\mathrm{n}=9)$ was $0.7 \mathrm{~J} / \mathrm{cm}^{2}$ for 30 $\mathrm{mg} / \mathrm{kg}(\mathrm{n}=3), 5.2 \mathrm{~J} / \mathrm{cm}^{2}$ for $20 \mathrm{mg} / \mathrm{kg}(\mathrm{n}=2), 5.0$ $\mathrm{J} / \mathrm{cm}^{2}$ for $10 \mathrm{mg} / \mathrm{kg}(\mathrm{n}=1), 30 \mathrm{~J} / \mathrm{cm}^{2}$ for $5 \mathrm{mg} / \mathrm{kg}$ $(\mathrm{n}=2)$, and $40 \mathrm{~J} / \mathrm{cm}^{2}$ for $500 \mathrm{mg}$ locally $(\mathrm{n}=1)$. Twenty four hours after sensitisation in all patients tested ( $\mathrm{n}=9)$, MPD reached baseline levels of $39.5 \mathrm{~J} / \mathrm{cm}^{2}$ (MDP before sensitisation $\left.40.4 \mathrm{~J} / \mathrm{cm}^{2}\right)$.

Nausea and vomiting

Four patients complained of nausea or vomiting after sensitisation with $20 \mathrm{mg} / \mathrm{kg}(\mathrm{n}=2)$ or $30 \mathrm{mg} / \mathrm{kg}(\mathrm{n}=2)$, respectively.

Increase in liver enzymes

In two patients, liver enzymes increased 24 hours after sensitisation with 20 and $30 \mathrm{mg} / \mathrm{kg}$ 5-ALA, respectively, up to threefold their index values. In both cases enzymes normalised within one week. In one patient steatosis of the liver was diagnosed by ultrasonography but liver enzymes were normal before sensitisation.

Decrease in blood pressure

Blood pressure was not significantly decreased and was stable after both local and systemic 5-ALA administration. However, with 30 $\mathrm{mg} / \mathrm{kg}$ 5-ALA a trend for a slight decrease in systolic blood pressure was seen but this was not significant. No patient complained of circulatory disorders.

PHARMACOKINETIC STUDIES

The total amount of porphyrins in serum correlated with the dose of drug used. While local application and sensitisation with 5 $\mathrm{mg} / \mathrm{kg}$ 5-ALA produced serum levels of 926 $\mathrm{pg} / \mathrm{ml}$ and $821 \mathrm{pg} / \mathrm{ml}$, respectively, 10, 20, and $30 \mathrm{mg} / \mathrm{kg}$ were followed by higher serum 
concentrations of porphyrins 24 hours after sensitisation: 1488, 1163, and $1716 \mathrm{pg} / \mathrm{ml}$, respectively.

\section{Discussion}

Optical guided biopsies may be an ideal method of identifying non-visible precancerous lesions in Barrett's oesophagus. Laser induced fluorescence spectroscopy (LIFS) could play a beneficial role in the detection of these lesions. Using this technique, laser light is directed via a fibre which is inserted through the biopsy channel of an endoscope to the tissue examined.

Panjehpour et al used LIFS with a differential normalised fluorescence index technique to differentiate between HGD and LGD or nondysplastic mucosa. Using this technique, autofluorescence of 36 patients was examined and $96 \%$ of non-dysplastic Barrett's oesophagus samples were correctly classified as benign, all LGD as benign, and $90 \%$ of HGD samples as premalignant. ${ }^{14}$ Von Holstein et al used a combination of endogenous and exogenous fluorophores $(0.35 \mathrm{mg} / \mathrm{kg}$ Photofrin) to discriminate between LGD, HGD, or adenocarcinoma and normal oesophageal and gastric mucosa by LIFS. They used the ratio of autofluorescence and porphyrin fluorescence intensity. The highest ratio was found for adenocarcinoma (0.78) and HGD (0.79) whereas those with moderate dysplasia $(0.21)$, normal gastric mucosa (0.07), and normal oesophageal mucosa $(0.10)$ were significantly lower. ${ }^{15}$ Recently, Eker et al found that in patients sensitised with 5-ALA, discrimination of polyps was more reliable than in patients without sensitiser. ${ }^{16}$ However, LIFS is still associated with a "sampling error" as the mucosa must be screened with a fibre. Therefore, direct visualisation of fluorescence in tumours seems to be more attractive.

In an animal model, fluorescence localisation of early colonic cancers in rats was possible with the naked eye. ${ }^{17}$ Bjorkman et al examined the colon 24 hours after sensitisation with 5 $\mathrm{mg} / \mathrm{kg}$ haematoporphyrins (HPD). Of all fluorescent tissues, only $20 \%$ had cancer and no dysplasia was detected using this sensitiser. Lowering the HPD dose to $3 \mathrm{mg} / \mathrm{kg}$ intravenously and increasing the time between sensitisation and fluorescence detection, the number of false positive fluorescence specimens decreased in the same tumour model. ${ }^{18}$ In a colitis animal model, we recently demonstrated that after sensitisation with 5-ALA, even detection of dysplasia is possible with the naked eye. Sensitivity and specificity depended strongly on the dose of 5-ALA used. ${ }^{11}$

In a recent pilot study, we described fluorescence endoscopy after 5-ALA sensitisation for detection of precancerous lesions in the gastrointestinal tract. ${ }^{12}$ Based on these promising results, we have now tested EFD in 58 examinations in patients with Barrett's oesophagus to visualise LGD, HGD, or non-visible early cancer. Different concentrations of 5-ALA were used as our animal experiments demonstrated a correlation between sensitivity and specificity for detection of dysplasia with the 5-ALA dose used. From the first pilot study on the gastrointestinal tract, we knew that the dose necessary for fluorescence diagnosis must be lower than the dose used for therapeutic purposes. ${ }^{19}$ Therefore, we choose doses ranging from 5 to $30 \mathrm{mg} / \mathrm{kg}$. After the first 20 patients, interim data analysis was performed. We found that 5 -ALA $5 \mathrm{mg} / \mathrm{kg}$ was too low to detect dysplasia and $30 \mathrm{mg} / \mathrm{kg}$ was too high as sensitivity compared with $20 \mathrm{mg} / \mathrm{kg}$ was not improved much and specificity decreased. The correlation of sensitivity and specificity with 5-ALA dose was analogous to our animal experiments. Consequently, most of the following patients were sensitised with 10 and $20 \mathrm{mg} / \mathrm{kg} 5$-ALA. Additionally, we tested local application of 5-ALA by spraying the substance with a special catheter onto the mucosa. In addition to the 10 patients with known dysplasia, we detected two additional early cancers and/or dysplasia in three patients using EFD. Thirty three of 243 biopsies contained either LGD or HGD/ carcinoma. After local sensitisation we missed $3 / 7 \mathrm{LGD}$ and $2 / 3 \mathrm{HGD} /$ carcinoma. After systemic sensitisation with $20 \mathrm{mg} / \mathrm{kg}$ or more, neither LGD nor HGD/carcinoma was missed but $2 / 5 \mathrm{LGD}$ and $1 / 10 \mathrm{HGD} /$ carcinoma after sensitisation with $10 \mathrm{mg} / \mathrm{kg}$. The high rate of false positive fluorescence was mainly caused by the higher drug dose which induced disturbing background fluorescence caused mainly by inflammation. Other limiting factors responsible for false positive fluorescence were the margin of ulcers, metaplasia, and reflux of bile into the oesophagus, which also induces strong red fluorescence. The local sensitisation mode had the best specificity but a lower sensitivity compared with systemic sensitisation. Ortner et al used local sensitisation for diagnosis of dysplasia in Barrett's oesophagus by LIFS. With time gated detection of PPIX fluorescence, sensitivity and specificity for discrimination between dysplasia and inflammation was $100 \%$ and $76 \%$, respectively. ${ }^{20}$ Local sensitisation however has the disadvantage of two endoscopies which is not practical for diagnostic purposes. A dose between 10 and 20 $\mathrm{mg} / \mathrm{kg}$ (for example, $15 \mathrm{mg} / \mathrm{kg}$ ) revealed a sensitivity somewhere between 80 and $100 \%$ and a specificity of about $55 \%$. If dysplasia and carcinoma produce PPIX earlier than normal or inflamed tissue, shortening of the time interval (that is, three hours) between sensitisation and endoscopy may result in better specificity without a decrease in sensitivity.

Findings of fluorescence of corresponding histology sections were encouraging. While epithelial fluorescence exceeded dysplastic lesions, the additional lesions detected (intestinal metaplasias) are considered preneoplastic in Barrett's mucosa. While we are still at the beginning of our understanding of the selective metabolism of PPIX in tumour cells, ${ }^{21}$ further organ specific features have to be taken into account. Our own observations showed different fluorescent intensities of oesophageal, gastric, duodenal, and colonic mucosa at given systemic concentrations of 5-ALA (unpublished data) and are in accordance with differences between for 
example squamous epithelium and urothelium, as shown for the urinary bladder. ${ }^{22}$

Because of the low number of side effects, this new diagnostic tool is most attractive. While local sensitisation caused no side effects, systemic sensitisation with $20 \mathrm{mg} / \mathrm{kg}$ or more caused mild nausea or vomiting in four and transient increases in liver enzymes in two cases. In all patients, skin photosensitivity was observed six hours after systemic administration, except for local sensitisation, but none of our patients was still light sensitive 18 hours later.

EFD may have the advantage of less biopsies to detect dysplasia. Furthermore, apart from better surveillance, those patients treated with PDT because of HGD may be better monitored after treatment compared with conventional biopsy strategies.

Meanwhile, autofluorescence has been used to detect precancerous lesions in the gastrointestinal tract. Sensitivity and specificity of $87 \%$ in the detection of $\mathrm{HGD} /$ carcinoma were found for this technique with laser induced fluorescence endoscopy (LIFE) but only 4/22 (18\%) LGD were detected (LIFE; Olympus Optical and Xillix Technologies). ${ }^{23}$ The advantage of no sensitisation is however reduced by the enormous costs of this system. At the moment it is unclear if LGD can be detected with LIFE, which may be possible with EFD, as shown by our own study. However, at the moment the numbers of patients examined with both techniques are too low to say which technique is more sensitive.

EFD is an interesting approach which allows visualisation of $\mathrm{HGD}$ /cancer but also LGD in Barrett's oesophagus. It may reduce sampling error and optimise surveillance in these patients. While local sensitisation had the lowest sensitivity but highest specificity and no side effects, systemic sensitisation with concentrations of $20 \mathrm{mg} / \mathrm{kg}$ or more cannot be recommended because of low specificity and increasing side effects. A randomised prospective trial has been initiated and is mandatory to demonstrate the benefit of EFD after sensitisation with 5-ALA compared with the standard technique of white light endoscopy with random biopsies in the four quadrants every $1-2 \mathrm{~cm}$.

1 Robertson CS, Mayberry JF, Nicholson DA, et al. Value of endoscopic surveillance in the detection of neoplastic change in Barrett's esophagus. Br F Surg 1988;128:108195.

2 Spechler SJ. Endoscopic surveillance for patients with Barrett's esophagus: Does the risk justify the practice? Ann rett's esophagus: Does the
Intern Med 1987;106:902-4.
3 Hameetman W, Tytgat GNJ, Houthoff HJ, et al. Barrett's esophagus: development of dysplasia and adenocarcinoma. Gastroenterology 1989;96:1249-56.

4 Drewitz DJ, Sampliner RE, Garewal HS. The incidence of adenocarcinoma in Barrett's esophagus: a prospective study of 170 patients followed 4.8 years. Am $\mathcal{F}$ Gastroenterol 1997;92:212-15.

5 McArdleJE, Lewin KJ, Randall G, et al. Distribution of dysplasia and early invasive carcinoma in Barrett's esophagus. Hum Pathol 1992;23:479-82.

6 Sampliner RE. Practice guidelines on the diagnosis, surveillance, and therapy of Barrett's esophagus. The Practice Parameters Committee of the American College of Gastroenterology. Am ₹ Gastroenterol 1998;93:1028-32.

7 Levine DS, Haggitt RC, Blount PL, et al. An endoscopic biopsy protocol can differentiate high-grade dysplasia from early adenocarcinoma in Barrett's esophagus. Gastroenterology 1993;105:40-50.

8 Falk GW, Rice TW, Goldblum JR, et al. Jumbo biopsy forceps protocol still misses unsuspected cancer in Barrett's esophagus with high-grade dysplasia. Gastrointest Endosc 1999;49:170-6.

9 Peng Q, Warloe T, Berg K, et al. 5-Aminolevulinic acid-based photodynamic therapy. Clinical research and future challenges. Cancer 1997;79:2282-308.

10 Regula J, MacRobert AJ, Gorchein A, et al. Photosensitisation and photodynamic therapy of oesophageal, duodenal, and colorectal tumours using 5 aminolaevulinic acid nd colorectal tumours using 5 aminolaevulinic acid $67-75$.

11 Messmann H, Kullmann F, Wild T, et al. Detection of dysplastic lesions by fluorescence in a model of colitis in rats after previous photosensitization with 5-aminolaevulinic acid. Endoscopy 1998;30:333-8.

12 Messmann H, Knüchel R, Bäumler W, et al. Endoscopic fluorescence detection of dysplasia in patients with Barrett's esophagus, ulcerative colitis, or adenomatous polyps after 5-aminolevulinic acid-induced protoporphyrin IX yps after 5-aminolevulinic acid-induced protoporp

13 Messmann H, Szeimies RM, Bäumler W, et al. Enhancement of the PDT effect in patients with esophageal cance by laser light fractionation. Endoscopy 1997;29:275-80.

14 Panjehpour M, Overholt BF, Vo-Dinh T, et al. Endoscopic fluorescence detection of high-grade dysplasia in Barrett's esophagus. Gastroenterology 1996;111:93-101.

15 Von Holstein CS, Nilsson AM, Andersson-Engels S, et al. Detection of adenocarcinoma in Barrett's oesophagus by means of laser induced fluorescence. Gut 1996;39:711-16.

16 Eker C, Montan S, Jaramillo E, et al. Clinical spectral characterisation of colonic mucosal lesions using autofluorescence and delta aminolevulinic acid sensitisation. Gut 1999;44:511-18

17 Bjorkman DJ, Samowitz W, Brigham E, et al. Fluorescence localization of early colonic cancer in the rat by hematoporphyrin derivative. Lasers Surg Med 1991;11:26370.

18 Von Rueden DG, McBrearty FX, Clements BM, et al. Photodetection of carcinoma of the colon in a rat model: a pilot study. F Surg Oncol 1993;53:43-6.

19 Messmann H, Mlkvy P, Montan S, et al. Endoscopic and microscopic fluorescence studies in patients with ulcerative colitis after 5-amino laevulinic acid photosensitisation. Gastroenterology 1995;108:506A.

20 Ortner M, Ebert B, Nolte D, et al. Endoscopic investigation of Barrett's esophagus by laser-induced fluorescence spectroscopy. Endoscopy 1997;29:E1.

21 Krieg R, Bechmann V, Fickweiler S, et al. Influence of subcellular protoporphyrin IX (PPIX) localisation on photocellular protoporphyrin IX (PPIX) localisation on phototoxicity in different human cology 1999;116:A443.

22 Steinbach P, Weingandt H, Baumgartner R, et al. Cellular fluorescence of the endogenous photosensitiser protoporphyrin IX following exposure to 5-aminolevulinic acid. Photochem Photobiol 1995;62:887-95.

23 Haringsma J, Van Ierland, Van Leeuwen $M$, et al. Localization of dysplasia using real-time light-induced fluorescence endoscopy. Endoscopy 1997;29:E35.

24 Haringsma J, Prawirodirdjo W, Tytgat GNJ. Accuracy of fluorescence imaging of dysplasia in Barrett's esophagus. Gastroenterology 1999;116:A418. 